\title{
Sintomas visuais de deficiências simples e múltiplas de micronutrientes em Antúrio (')
}

\author{
PAULO JORGE DE PINHO(2); JUSSARA ELLEN MORAIS FRAZÃO(3); GUILHERME AMARAL DE SOUZA(4); \\ JANICE GUEDES DE CARVALHO(5); ANA ROSA RIBEIRO BASTOS(6) ${ }^{(6}$ NILMA PORTELA OLIVEIRA(7)
}

\begin{abstract}
RESUMO
Informações sobre a nutrição de plantas ornamentais ainda deixam grandes lacunas quanto às exigências nutricionais e à identificação de problemas na produção e na qualidade do produto decorrentes de estresses nutricionais, deficiências ou excessos. O objetivo deste trabalho foi a caracterização dos sintomas visuais de deficiências nutricionais simples e múltiplas e seus efeitos no crescimento de antúrio. O delineamento experimental utilizado foi o inteiramente casualizado, com 12 tratamentos e quatro repetições. Os tratamentos consistiram de: Solução nutritiva de HOAGLAND e ARNON (1950) completa, solução com omissão de B (-B), com omissão de $\mathrm{Cu}$ (-Cu), com omissão de $\mathrm{Fe}$ (-Fe), com omissão de $\mathrm{Mn}$ (-Mn), com omissão de Zn (-Zn), com omissão de B e Cu (-B Cu), com omissão de B e Mn (-B Mn), com omissão de B e Zn (-B $\mathrm{Zn}$ ), com omissão de $\mathrm{Fe}$ e $\mathrm{Mn}$ (-Fe Mn), com omissão de $\mathrm{Zn}$ e $\mathrm{Cu}$ (-Zn Cu) e com omissão de $\mathrm{Zn}$, Cu e $\mathrm{Fe}$ (-Zn Cu Fe). Com as manifestações dos sintomas visuais de deficiências nutricionais, fotografou-se e anotou-se as alterações nas folhas, raízes e flores. Por ocasião da colheita, foram avaliados número de folhas, comprimento e largura da maior folha. As plantas foram divididas em folhas, caule, raiz e flores. Determinou-se o peso da matéria seca das partes das plantas. Os dados obtidos foram submetidos a análise de variância e as médias comparadas pelo teste de Scott e Knott $(\mathrm{p} \leq 0,05)$. De forma geral, a omissão de $\mathrm{B}$ de forma isolada ou em combinações causou alterações morfológicas traduzidas em sintomas visuais de deficiências típicos desse nutriente. Há dominância dos sintomas de deficiência de B quando esse nutriente é omitido em conjunto com outros nutrientes. A omissão conjunta de B e Mn causou as maiores reduções na produção de matéria seca de folhas. As omissões que acarretaram as maiores reduções no número de folhas foram as omissões múltiplas de $\mathrm{Zn}$ e $\mathrm{Cu}, \mathrm{Fe}$ e $\mathrm{Mn}$, B e $\mathrm{Mn}$ e as omissões simples de $\mathrm{Mn}$ e de $\mathrm{Zn}$ acarretaram as maiores reduções no número de folhas. As maiores reduções na largura de folhas estão sempre associadas às omissões de $\mathrm{B}$ tanto de forma simples quanto múltiplas. O comprimento de folhas foi afetado em maior intensidade pelas omissões simples de B e Mn e múltiplas de B e Cu, B e Mn e B e Zn.
\end{abstract}

Palavras-chave: diagnose visual, solução nutritiva, nutrição mineral, Anthurium andraeanum.

\section{ABSTRACT \\ Simple and multiple visual symptoms of micronutrients deficiency in Anthurium andraeanum}

\begin{abstract}
Mineral nutrition information of the ornamental plants still leaves great gaps on nutritional requirements and the identification of problems in the production and the product quality, due to nutritional stress, deficiencies or excesses. The objective of this work was the characterization visual symptoms of simple and multiple nutritional deficiencies, and their effects on anthurium growth. The experiment following a completely randomized design with 12 treatments and four replicates. Treatments consisted of: HOAGLAND and ARNON (1950) complete solution, with B omission (-B), with $\mathrm{Cu}$ omission (-Cu), with Fe omission (-Fe), with Mn omission (-Mn), with $\mathrm{Zn}$ omission (-Zn), with $\mathrm{B}$ and $\mathrm{Cu}$ omission (-B Cu), with $\mathrm{B}$ and $\mathrm{Mn}$ omission (-B Mn), with B and $\mathrm{Zn}$ omission (-B Zn), with Fe and Mn omission (-Fe Mn), with $\mathrm{Zn}$ and $\mathrm{Cu}$ omission (-Zn $\mathrm{Cu}$ ), and with $\mathrm{Zn}, \mathrm{Cu}$ and $\mathrm{Fe}$ omission ( $\mathrm{Zn} \mathrm{Cu} \mathrm{Fe}$ ). The plants were observed verifying the changes resulted from the nutrient omissions. The symptoms in leaves, roots, and flowers were characterized and photographed. At harvest, were evaluated the number of leaves, length and width of the largest leaf. The plants were divided into leaves, stems, roots, and flowers. Were calculated the dry matter weight of plant's parts. The obtained data were submitted to analyses of variance (ANOVA), as well as Scott e Knott test $(\mathrm{p} \leq 0,05)$. In general, the simple and combined B omission caused morphological changes reflected in typical deficiency symptoms of this nutrient. There is dominance of the symptoms of B deficiency when this nutrient is omitted together with other nutrients. The omission of joint B and Mn caused the greater reductions in dry matter production of leaves. Omissions that led to major reductions in the number leaves were multiple omissions of $\mathrm{Zn}$ and $\mathrm{Cu}, \mathrm{Fe}$ and $\mathrm{Mn}, \mathrm{B}$ and $\mathrm{Mn}$ and omissions simple $\mathrm{Mn}$ and $\mathrm{Zn}$ led to the largest reductions in leaf number. The greater reductions in the width of leaves are always $\mathrm{B}$ omissions associated with both a simple as multiple omissions. The length of leaves was affected to a greater intensity by simple omissions of $\mathrm{B}$ and $\mathrm{Mn}$ and multiple $\mathrm{B}$ and $\mathrm{Cu}, \mathrm{Mn}$ and $\mathrm{B}$, and $\mathrm{B}$ and $\mathrm{Zn}$.
\end{abstract}

Keywords: visual diagnosis, culture solution, mineral nutrition, Anthurium andraeanum.

\footnotetext{
(1) Recebido em 10/12/2009 e aceito para publicação em 20/05/2011. Trabalho financiado pela Fundação de Amparo à Pesquisa do Estado de Minas Gerais FAPEMIG.

(2) Eng ${ }^{\circ}$. Agro ${ }^{\circ}$ D.Sc. Ciência do Solo, Bolsista Pós-doutorado FAPEMIG, Universidade Federal de Lavras, Departamento de Ciência do Solo, CP 3037 , Lavras-MG. 37200-000. Endereço eletrônico: pinhopj@yahoo.com.br.

${ }^{(3)}$ Lic. em Ciências Agrárias, D.Sc. Ciência do Solo, Bolsista Pós-doutorado FAPEMIG, Rod. BR 494, Km 02, Colônia de Bengo, Ctan, Campus 3 da Universidade Federal de São João Del Rei, São João Del Rei-MG. 36300-000. Endereço eletrônico: jmoraisfrazao@yahoo.com.br

${ }^{(4)} \mathrm{Eng}^{\mathrm{o}}$. Agro . M.Sc. Ciência do Solo, Doutorando em Ciência do Solo, Bolsista CNPq, Universidade Federal de Lavras, Departamento de Ciência do Solo, CP 3037, Lavras-MG. 37200-000. Endereço eletrônico: amaralufla@gmail.com.

${ }^{(5)}$ Eng $^{\text {a }}$. Agr ${ }^{\text {a }}$ D.Sc. Solos e Nutrição de Plantas, Professora Titular, Bolsista CNPq, Universidade Federal de Lavras, Departamento de Ciência do Solo, CP 3037, Lavras-MG. 37200-000. Endereço eletrônico: janicegc@ufla.br

${ }^{\left({ }^{(}\right)} \mathrm{Eng}^{\mathrm{a}}$. Agr ${ }^{\mathrm{a}}$. D.Sc. Solos e Nutrição de Plantas, Bolsista Pós-doutorado CAPES/PNPD, Universidade Federal de Lavras, Departamento de Ciência do Solo, CP 3037, Lavras-MG. 37200-000. Endereço eletrônico: arosa@ufla.br

${ }^{(7)} \mathrm{Eng}^{\mathrm{a}}$. Agra ${ }^{\mathrm{a}}$. M.Sc. Ciência do Solo, Doutoranda em Ciência do Solo, Bolsista CNPq, Universidade Federal de Lavras, Departamento de Ciência do

Solo, CP 3037, Lavras-MG. 37200-000. Endereço eletrônico: nilmaportela@yahoo.com.br
} 


\section{INTRODUÇÃO}

A floricultura, em seu sentido mais amplo, abrange o cultivo de flores e plantas ornamentais com variados fins que incluem desde as culturas de flores para corte à produção de mudas arbóreas de porte elevado (CASTRO, 1998). A diversidade e a amplitude de climas e solos no Brasil permitem cultivos de inúmeras espécies de flores e plantas ornamentais, de diversas origens, tanto nativas quanto de clima temperado e tropical (KIYUNA et al., 2006), o país apresenta ainda vantagens como disponibilidade de terras, água, energia e mão-de-obra (ARRUDA et al., 1996).

Vários fatores estão envolvidos na qualidade dos produtos da floricultura, destacando-se entre eles a adubação e a nutrição das plantas (FURLANI e CASTRO, 2001).

A avaliação do estado nutricional das plantas é uma poderosa ferramenta para o manejo adequado das culturas. Dentre as formas de avaliação do estado nutricional destacase a diagnose visual. Essa diagnose consiste em comparar o aspecto da amostra com o do padrão (MALAVOLTA et al., 1997). Entretanto, três fatos tornam a diagnose visual de difícil aplicação tendo apenas a sintomatologia como base: 1) os sintomas de determinado elemento podem diferir de tal forma em diferentes culturas que o conhecimento desses sintomas em uma espécie oferece pouca ou nenhuma ajuda na determinação da mesma deficiência em outro; 2) sintomas semelhantes ou similares podem resultar de deficiências de diferentes nutrientes; 3) deficiências múltiplas, ou seja, de dois ou mais nutrientes, podem ocorrer em campo dificultando a diagnose, visto que, em sua maioria é descrita na literatura de forma isolada (EPSTEIN e BLOOM, 2004).

A diagnose torna-se mais eficiente com a caracterização dos sintomas visuais de deficiência ou toxicidade de cada nutriente, para uma determinada cultura, acompanhada com fotos coloridas, constituindo-se num importante instrumento de diagnose do estado nutricional das plantas (CARVALHO e VIÉGAS, 2004).

Com o aumento das exportações de plantas ornamentais, trabalhos que visem melhorias na qualidade dos produtos colhidos tornam-se essenciais. Assim, o objetivo deste trabalho foi caracterizar os sintomas visuais de deficiências simples e múltiplas e seus efeitos no crescimento e desenvolvimento das plantas de antúrio.

\section{MATERIAL E MÉTODOS}

O experimento foi conduzido em casa de vegetação do Departamento de Ciência do Solo da Universidade Federal de Lavras (Lavras-MG), definida geograficamente pelas coordenadas de $21^{\circ} 14^{\prime}$ 'de latitude sul e $45^{\circ} 00^{\prime}$ 'de longitude oeste, altitude de $918 \mathrm{~m}$.

$\mathrm{O}$ delineamento experimental foi inteiramente casualizado, com 12 tratamentos e quatro repetições, representados por: solução nutritiva de HOAGLAND e ARNON (1950) completa, solução com omissão de B (-B), solução com omissão de $\mathrm{Cu}(-\mathrm{Cu})$, solução com omissão de $\mathrm{Fe}$ (-Fe), solução com omissão de $\mathrm{Mn}(-\mathrm{Mn})$, solução com omissão de Zn (-Zn), solução com omissão de B e Cu
(-B Cu), solução com omissão de B e Mn (-B Mn), solução com omissão de B e Zn (-B Zn), solução com omissão de $\mathrm{Fe}$ e Mn (-Fe Mn), solução com omissão de $\mathrm{Zn}$ e $\mathrm{Cu}(-\mathrm{Zn}$ B) e solução com omissão de $\mathrm{Zn}, \mathrm{Cu}$ e $\mathrm{Fe}(-\mathrm{Zn} \mathrm{Cu} \mathrm{Fe})$.

Foram utilizadas mudas de antúrio da cultivar Juréia IAC-05 com aproximadamente $5 \mathrm{~cm}$ de altura as quais passaram por um período de adaptação à solução nutritiva, sob sombrite, e uniformização em bandejas de plástico. As mudas permaneceram por 30 dias em solução nutritiva de HOAGLAND e ARNON (1950) a 20\% de sua força iônica.

Após o período de adaptação as plantas foram submetidas aos tratamentos. As plantas foram transplantadas para vasos plásticos com capacidade de $3 \mathrm{~L}$, mantidas sob aeração constante. Foram utilizadas placas de isopor de $30 \mathrm{~cm}$ de diâmetro e $2 \mathrm{~cm}$ de espessura como suporte para as plantas. As soluções eram trocadas quinzenalmente durante o período experimental.

No preparo de todas as soluções estoque empregouse reagentes para análise. As soluções nutritivas foram preparadas utilizando-se água deionizada e, durante o intervalo de renovação das soluções, o volume dos vasos foi completado, sempre que necessário, utilizando-se água deionizada.

À medida que ocorriam as manifestações dos sintomas visuais de deficiências nutricionais essas foram fotografadas e anotadas todas as alterações nas folhas, hastes, raízes e flores que distinguiam as plantas sob omissão de nutrientes das plantas cultivadas em solução completa. Dessa forma foi possível acompanhar a evolução dos sintomas visuais de deficiências.

Após a manifestação dos sintomas de deficiência foi realizada a colheita das plantas, após um período de 2 anos de condução do experimento, separando-as em folhas, caule, raiz e flores. Na ocasião da colheita foram realizadas avaliações do número de folhas e, a largura e comprimento da maior folha. As diferentes partes das plantas foram secas em estufa de circulação forçada de ar, à temperatura de 65$70^{\circ} \mathrm{C}$ por $72 \mathrm{~h}$ ou até que apresentasse peso constante. $\mathrm{O}$ material vegetal foi pesado em balança de precisão $(0,01 \mathrm{~g})$ para a obtenção do peso de matéria seca.

Os resultados foram submetidos à análise de variância e as médias dos tratamentos comparadas pelo teste de Scott e Knott a 5\%. As análises estatísticas foram realizadas com o programa computacional Sisvar (FERREIRA, 2003).

\section{RESULTADOS E DISCUSSÃO}

\section{Caracterização dos sintomas visuais de deficiências nutricionais}

\section{Deficiência de boro (B)}

Foi observado que sob deficiência de $\mathrm{B}$ as plantas apresentaram diminuição do crescimento. As plantas apresentaram, inicialmente, folhas mais novas com cor verde-escura e mais espessas, com nervuras nitidamente salientes. Com a evolução dos sintomas, as plantas lançavam folhas novas mal formadas, apresentando o limbo com aspecto encarquilhado (Figura 1A). Com a intensificação desses sintomas ocorreu superbrotação na base das plantas. Da mesma forma com que ocorreu com as folhas, as flores 
formadas por plantas sob carência de B apresentaram várias deformações. O sistema radicular apresentou diminuição na formação de novas raízes, conferindo a esse um aspecto menos denso. Sintomas semelhantes foram observados em bananeira ornamental (Musa velutina) por PINHO (2007) e em bastão-do-imperador (Etlingera elatior) por FRAZÃO (2008).

Segundo MENGEL e KIRKBY (1987) a deficiência de B surge inicialmente como um crescimento anormal ou retardado de pontos em crescimento, devido provavelmente ao envolvimento do nutriente no metabolismo de fenóis e ácido indol-acético que pode causar até a morte dos pontos de crescimento e necrose em folhas novas. Em revisão sobre a redistribuição de B em plantas, BASTOS e CARVALHO (2004) relatam que devido à relativa imobilidade nos tecidos, a sua deficiência tem como uma característica comum os distúrbios do crescimento dos tecidos meristemáticos. MALAVOLTA et al. (1997) mencionam que sob omissão de $\mathrm{B}$, as dificuldades de divisão e diferenciação celulares são as primeiras indicações da carência, resultantes da necessidade do nutriente para a síntese das bases nitrogenadas.

\section{Deficiência de cobre ( $\mathrm{Cu})$}

Sob deficiência de $\mathrm{Cu}$ as plantas apresentaram diminuição do crescimento (Figura 1B) e ainda diminuição do número de folhas lançadas sendo que estas eram encarquilhadas e mais espessas quando comparadas às folhas de plantas do tratamento completo.

As raízes das plantas sob carência de $\mathrm{Cu}$ apresentaram diminuição no crescimento, conferindo um aspecto menos denso ao sistema radicular, além de raízes com coloração mais escura.

$\mathrm{O} \mathrm{Cu}$ atua na síntese de proteínas, diminuindo em plantas deficientes, o que pode ser devido ao seu papel como co-fator para a síntese de enzimas do DNA e RNA. $\mathrm{O}$ nutriente atua ainda no metabolismo de carboidratos (MALAVOLTA, 1980). O nutriente é considerado pouco móvel no floema, motivo pelo qual os sintomas de deficiências em geral mostram-se nas folhas mais novas (MALAVOLTA et al., 1997).

\section{Deficiência de ferro ( $\mathrm{Fe})$}

A principal função do Fe é a ativação de enzimas, atuando como grupo prostético. Participa de reações fundamentais de oxidorredução, e é catalisador da biossíntese de clorofila. O sintoma visual mais característico da deficiência desse nutriente é uma clorose internerval intensa, onde somente as nervuras permanecem verdes e, dependendo da sua intensidade, até mesmo as nervuras tornam-se pálidas (DECHEN e NACHTIGALL, 2006).

Entretanto, foi observado que sob deficiência de $\mathrm{Fe}$ as plantas apresentaram uma diminuição do porte, apresentando ainda, menor número de folhas sem apresentarem clorose internerval.

Pôde-se observar que o sistema radicular apresentou alguns pontos com coloração ferruginosa e com extremidades necrosadas (Figura 1C). BERGMANN (1992) menciona que o sistema radicular de plantas sob omissão de Fe é afetado. A deficiência de Fe está associada com a inibição da elongação radicular, aumentos do diâmetro das zonas apicais das raízes, formação abundante de raízes laterais e cor amarelada devido ao acúmulo de riboflavina, sendo essa uma estratégia para translocar Fe das raízes para a parte aérea (RÖMHELD e MARSCHNER, 1981).

\section{Deficiência de manganês (Mn)}

As plantas sob omissão desse nutriente apresentaram menor porte, quando comparadas às plantas do tratamento completo. Entretanto, da mesma forma com que ocorreu para o tratamento $-\mathrm{Fe}$, não houve a manifestação característica do sintoma visual da deficiência nutricional de Mn.

Devido à variedade de processos metabólicos envolvendo o Mn é difícil definir as relações entre a deficiência, efeitos fisiológicos e sintomas. Entretanto, assume-se que a clorose associada à deficiência desse nutriente é uma conseqüência de deficiência de energia. A diminuição das sínteses e aceleradas quebras de proteínas e clorofila levam ao acúmulo de compostos nitrogenados de baixo peso molecular que culminam finalmente em necroses (BERGMANN, 1992).

$\mathrm{O}$ nutriente está ligado à síntese de clorofila, e a maior parte do nutriente encontra-se nos cloroplastos, participando de processos de transporte eletrônico na fase luminosa da fotossíntese (MENGEL e KIRKBY, 1987; MARSCHNER, 1995) e sob omissão de Mn a estrutura dos cloroplastos é alterada (MALAVOLTA et al., 1997).

Inicialmente o sistema radicular das plantas sob omissão de Mn teve menor crescimento. Com o avanço da carência ocorreram necroses nos ápices das raízes diminuindo o número dessas e acarretando uma severa diminuição do volume do sistema radicular (Figura 1D).

\section{Deficiência de zinco ( $\mathrm{Zn})$}

Inicialmente a deficiência de Zn causou redução do porte das plantas, conferindo ainda menor número de folhas. As folhas de plantas sob carência de $\mathrm{Zn}$ apresentaram aspecto encarquilhado e deformadas (Figura 1E).

As funções mais conhecidas do $\mathrm{Zn}$ em plantas superiores são na participação da síntese do triptofano, que por sua vez é precursor do ácido-indolacético; inibição da atividade das RNAse; participação na redução do nitrato e na síntese de aminoácidos entre outras (MALAVOLTA et al., 1997). Assim, a carência de Zn provoca nanismo nas plantas além de folhas pequenas, estreitas e alongadas (MALAVOLTA, 2006).

As raízes apresentaram cor escura, necroses dos ápices acarretando menor volume, quando comparado com plantas do tratamento completo.

\section{Deficiência de boro e cobre}

De forma geral, os sintomas apresentados pela omissão de $\mathrm{B}$ e $\mathrm{Cu}$ foram semelhantes aos sintomas apresentados por plantas sob omissão simples de B. As plantas apresentaram porte reduzido. Com o avanço da carência as folhas mais novas eram mal formadas com maior espessura e encarquilhadas (Figura 1F).

As plantas sob omissão conjunta de $\mathrm{B}$ e Cu apresentaram sistema radicular menos volumoso e raízes escuras. 


\section{Deficiência de boro e manganês}

A redução do porte das plantas sob omissão conjunta de B e Mn foi o primeiro sintoma observado (Figura $1 \mathrm{G}$ ). Houve uma redução do número de folhas e com o avanço da carência as folhas novas apresentaram deformações, menor tamanho e encarquilhamento.

As raízes das plantas do tratamento -B $\mathrm{Mn}$ se apresentaram mais escuras e menos desenvolvidas conferindo ao sistema radicular aspecto menos volumoso. A redução do volume de raízes resultante da carência simultânea de B e Mn foi maior do que quando foi omitido somente Mn.

\section{Deficiência de boro e zinco}

A omissão de B e Zn acarretou uma redução do crescimento das plantas. Com o avanço da carência as folhas mais novas apresentaram aspecto coriáceo e encarquilhadas (Figura 1H). A medida que as plantas emitiam novas folhas essas eram mais estreitas nas pontas mantendo em sua base largura semelhante a de folhas assintomáticas, ou seja, apresentando folhas idênticas às de plantas mantidas sob o tratamento completo, sem omissão de nutrientes.

As raízes apresentaram cor mais escura e aparentemente menor volume quando comparadas as raízes de plantas do tratamento completo. A redução do volume de raízes resultante da carência simultânea de B e $\mathrm{Zn}$ foi maior do que quando foi omitido somente $\mathrm{Zn}$.

\section{Deficiência de ferro e manganês}

Da mesma forma com que ocorreu nos tratamentos onde os nutrientes foram omitidos de forma simples, quando esses foram omitidos de forma conjunta não foram observados sintomas visuais característicos de deficiências de ambos.

\section{Deficiência de cobre e zinco}

A redução do porte das plantas sob deficiências múltiplas de $\mathrm{Cu}$ e $\mathrm{Zn}$ foi o efeito mais evidente do tratamento. $\mathrm{O}$ número de folhas foi drasticamente reduzido, entretanto essas eram bastante largas e compridas. As plantas não apresentaram sintomas característicos de deficiências de $\mathrm{Cu}$ e $\mathrm{Zn}$ em suas folhas. Entretanto, as raízes de plantas sob carência de $\mathrm{Cu}$ e $\mathrm{Zn}$ eram mais escuras e menos volumosas quando comparadas as plantas do tratamento completo (Figura 1I).

Com o avanço da carência as plantas produziram flores com aspecto deformado, pequenas e enrugadas.

\section{Deficiência de cobre, ferro e zinco}

A omissão múltipla de $\mathrm{Cu}, \mathrm{Fe}$ e $\mathrm{Zn}$ não resultou em sintomas visuais de deficiências nutricionais de nenhum dos nutrientes. Dessa forma não foi possível caracterizar os sintomas múltiplos. Acredita-se que há a necessidade de ensaios com maior tempo de duração para obtenção dos resultados, tendo em vista o crescimento lento da espécie.

\section{Produção de matéria seca e parâmetros de crescimento}

\section{Produção de matéria seca}

A produção de matéria seca para as diferentes partes das plantas foi afetada pelos tratamentos (Tabela 1).

\section{Produção de matéria seca de folhas}

A menor produção de matéria seca de folhas (MSFO) foi observada no tratamento onde houve omissão conjunta de B e Mn. Houve uma redução na produção de MSFO de $74,99 \%$ quando comparado à produção do tratamento completo. De forma geral, a omissão simples de B e Mn não afetaram tanto a produção de MSFO como quando esses nutrientes foram omitidos de forma conjunta.

As maiores produções de MSFO foram observadas nos tratamentos completo, -B, -Fe, -Zn, -B Zn, -Fe Mn, $-\mathrm{Zn} \mathrm{Cu}$ e $-\mathrm{Zn} \mathrm{Cu} \mathrm{Fe}$ não havendo diferenças significativas entre esses. Entretanto, as médias de produção de MSFO das plantas do tratamento completo foram superiores a de todos os demais tratamentos.

\section{Produção de matéria seca de caule}

As menores produções de matéria seca de caule (MSCA) foram observadas nos tratamentos completo, -B, - $\mathrm{Cu},-\mathrm{Mn},-\mathrm{B} \mathrm{Cu},-\mathrm{B} \mathrm{Mn}$ e -Zn Cu (Tabela 1). Entretanto, deve-se levar em consideração que todos esses tratamentos apresentaram plantas de porte reduzido, em relação ao tratamento completo, conforme descrito na caracterização dos sintomas visuais de deficiências nutricionais. A maior produção de MSCA provavelmente foi devido ao aumento do diâmetro desse e não em altura, conferindo plantas de menor porte quando comparado a plantas do tratamento completo.

A maior produção de MSCA foi observada em plantas do tratamento -Fe, sendo que este valor foi 49,97\% superior à MSCA de plantas do tratamento completo.

\section{Produção de matéria seca de raiz}

A menor produção de matéria seca de raiz (MSRA) foi observada no tratamento sob omissão de $\mathrm{Cu}$. A redução da produção de MSRA foi de $75 \%$ em relação ao tratamento completo. $\mathrm{O} \mathrm{Cu}$ atua na síntese de proteínas, diminuindo em plantas deficientes, o que pode ser devido ao seu papel como co-fator para a síntese de enzimas, do DNA e RNA. $\mathrm{O}$ nutriente atua ainda no metabolismo de carboidratos (MALAVOLTA, 1980).

A maior produção de MSRA foi observada em plantas do tratamento completo, onde não foram omitidos nutrientes.

\section{Produção de matéria seca de flores}

As omissões simples de Fe Mn e suas associações não afetaram a produção de matéria seca de flores (MSFL). As maiores produções de MSFL foram observadas em plantas dos tratamentos -Fe, -Mn e-Fe Mn, representando $108,38 \%$, 58,38\% e 50\% respectivamente a mais da produção de MSFL do tratamento completo. Entretanto, essas flores produzidas apresentaram qualidade inferior, produzindo flores mal formadas impróprias para a comercialização. A cor e aparência das flores de antúrio talvez seja o aspecto mais importante da espécie em relação ao seu valor ornamental, por se tratar de uma planta utilizada para corte.

Os demais tratamentos não apresentaram diferenças significativas de produção de MSFL em relação ao tratamento completo, entretanto, ressalta-se o mesmo em relação a qualidade das flores produzidas. 


\section{Número de folhas}

$\mathrm{O}$ maior número de folhas foi observado nos tratamentos completo, -B, -Cu, -Fe, -B Cu, -B Zn, - Zn Cu Fe (Tabela 2).

Plantas sob omissão de B apresentaram várias brotações decorrentes da carência do nutriente, conforme apresentado na caracterização dos sintomas visuais de deficiências, que não acarretou diferenças significativas para a variável em relação ao tratamento completo. De todos os tratamentos onde foram omitidos o B, somente no tratamento - B Mn o número de folhas foi inferior ao do tratamento completo.

Os menores valores de número de folhas foram observados nos tratamentos -Mn, -Zn, -B Mn, -Fe Mn e - $\mathrm{Zn} \mathrm{Cu}$, representando respectivamente reduções de 32,94; 35,$22 ; 20,46 ; 26,12$ e 52,27\% em relação ao número de folhas do tratamento completo. Em todos os tratamentos onde foram omitidos $\mathrm{Mn}$, de forma simples ou múltipla, ocorreram os menores valores para essa variável.

Apesar de não haver diferenças significativas entre os tratamentos -Mn, - Zn, -B Mn, -Fe Mn e - Zn Cu, a menor média para o número de folhas ocorreu no tratamento sob omissão conjunta de $\mathrm{Zn}$ e $\mathrm{Cu}$. O $\mathrm{Zn}$ participa de várias sínteses bioquímicas nas plantas superiores. No metabolismo do DNA e no ácido ribonucléico (RNA), na divisão celular e síntese de proteínas (MARSCHNER, 1995).

\section{Comprimento da maior folha}

Os maiores valores para a variável comprimento da maior folha foram observados em plantas dos tratamentos - $\mathrm{Cu}$, -Fe, -Mn, -Fe Mn, -Zn Cu e - Zn Cu Fe, representando valores 20,$02 ; 8,57 ; 5,74 ; 8,57 ; 10,03 ; 20,02$ e $7,16 \%$ superiores aos observados para a média das maiores folhas de plantas do tratamento completo (Tabela 2).

Os menores valores para esta variável foram observados nas plantas do tratamento completo, -B, -B Cu, -B Mn e -B Zn. Desta forma, infere-se que a omissão de B parece influenciar mais o comprimento de forma negativa, tanto de forma simples quanto múltipla, que a omissão dos demais nutrientes. MALAVOLTA et al. (1997) mencionam que sob omissão de $\mathrm{B}$, as dificuldades de divisão e diferenciação celulares são as primeiras indicações da carência, resultantes da necessidade do nutriente para a síntese das bases nitrogenadas.

\section{Largura da maior folha}

A largura da maior folha foi afetada pelos tratamentos de forma semelhante ao que ocorreu para a variável comprimento da maior folha, conforme é mostrado na Tabela 2 .

Os maiores valores de largura da maior folha foram observados nos tratamentos $-\mathrm{Cu},-\mathrm{Fe},-\mathrm{Zn},-\mathrm{Fe} \mathrm{Mn},-\mathrm{Zn}$ $\mathrm{Cu}$ e $-\mathrm{Zn} \mathrm{Cu} \mathrm{Fe.}$

Os menores valores foram observados em plantas do tratamento completo, $-\mathrm{B},-\mathrm{Mn},-\mathrm{B} \mathrm{Cu},-\mathrm{B} \mathrm{Mn}$ e $-\mathrm{B} \mathrm{Zn}$, não havendo diferenças significativas entre os tratamentos. Embora não tenha havido diferenças significativas para essas variáveis, as folhas dos tratamentos sob omissão de nutrientes apresentaram deformações no limbo foliar quando comparados com folhas de plantas do tratamento completo.

\section{AGRADECIMENTOS}

Ao Fundo de Apoio à Pesquisa do Estado de Minas Gerais (FAPEMIG), pelo financiamento do projeto e concessão da bolsa de pós-doutorado do primeiro e segundo autor.

\section{REFERÊNCIAS}

ARRUDA, S. T.; OLIVETTE, M. P. A.; CASTrO, C. E. F. Diagnóstico da floricultura do Estado de São Paulo. Revista Brasileira de Horticultura Ornamental, Campinas, v. 2, n.2, p.1-18, 1996.

BASTOS, A. R. R. ; CARVALHO, J.G. Absorção radicular e redistribuição do boro pelas plantas e seu papel na parede celular. Revista Universidade Rural, Rio de Janeiro, v. 24, p.47-66, 2004.

BERGMANN, W. Nutritional disorders of plants: development, visual and analytical diagnosis. (1ed.) Jena: Gustav Fischer, 1992. 741p.

CARVALHO, J.G.; VIÉGAS, I.J.M. Caracterização de sintomas de deficiências de nutrientes em Paricá (Schizolobium amazonicum Huber ex. Ducke). Brasília: Embrapa, 2004. 6p. (Circular Técnica, 37).

CASTRO, C. E. F. Cadeia produtiva de flores e plantas ornamentais. Revista Brasileira de Horticultura Ornamental, Campinas, v.4, n.1/2, p.1-46, 1998.

DECHEN, A. R.; NACHTIGALL, G. R. Elementos essenciais e benéficos às plantas superiores. In: FERNADES, M. S. (Ed.). Nutrição mineral de plantas. Viçosa, MG: SBCS, 2006. p.1-5.

EPSTEIN, E.; BLOOM, A. Mineral nutrition of plants. (1ed.) Sunderland: Sinauear Associates, 2004. 403 p.

FERREIRA, D. F. SISVAR - Sistema de análises de variância para dados balanceados: programa de análises estatísticas e planejamento de experimentos, versão 4.6. Lavras: DEX/UFLA, 2003.

FURlANI, A. M. C.; CASTRO, C. E. F. Plantas ornamentais e flores. In: FERREIRA, M. E.; CRUZ, M. C. P.; RAIJ, B.; ABREU, C. A. Micronutrientes e elementos tóxicos na agricultura. Jaboticabal: CNPq/ FAPESP/ POTAFOS, 2001, p.533-552.

FRAZÃO, J. E. M. Diagnose da deficiência nutricional e crescimento do bastão-do-imperador (Etlingera elatior (Jack) R. M. Smith) com o uso da técnica do elemento faltante em solução nutritiva. Lavras: UFLA, 2008. 68p. Tese (Doutorado em Ciência do Solo).

HOAGLAND, D. R.; ARNON, D. L. The water culture methods for growing plants without soil. Berkeley: California Agricultural Experiment Station, 1950. 32 p. (Bulletin, 347) 
KIYUNA, I.; ÂNGELO, J. A., COELHO, P. J. Flores: comportamento do comércio exterior brasileiro no primeiro trimestre de 2006. Análises e indicadores do agronegócio. 2006. Disponível em: <http://www.iea.sp.gov.br/ out/ trabalhos.php?codAutor=25>. Acesso em: 23 jun. 2008.

MALAVOLTA, E. Elementos de nutrição mineral de plantas. (1.ed.) São Paulo: Ceres, 1980. 251p.

MALAVOLTA, E.; VITTI, G. C.; OLIVEIRA, S. A. de. Avaliação do estado nutricional das plantas: Princípios e aplicações. (2.ed.) Piracicaba: POTAFOS, 1997. 319p.

MALAVOLTA, E. Manual de nutrição mineral de plantas. (1.ed.) São Paulo: Ceres, 2006. 638 p.

MARSCHNER, H. Mineral nutrition of higher plants. (2.ed.). New York: Academic Press, 1995. 889p.

MENGEL, K.; KIRKBY, E. A. Principles of plant nutrition. (4.ed.) Bern: International Potash Institute, 1987. $687 \mathrm{p}$.

PINHO, P.J. Deficiências nutricionais em bananeira ornamental (Musa velutina $\mathrm{H}$. Wendl. e Drude): alterações químicas e morfológicas e caracterização de sintomas visuais, Lavras: UFLA, 2007. 147p. Tese (Doutorado em Ciência do Solo).

RÖMHELD, V.; MARSCHNER, H. Iron deficiency stress induced morphological and physiological changes inroot tips of sunflower. Physiologia Plantarum. Lund, v.53, p.354-360, 1981.

Tabela 1. Produção de matéria seca de folhas (MSFO), matéria seca de caule (MSCA), matéria seca de raiz (MSRA) e matéria seca de flores (MSFL) de plantas de antúrio, sob omissão de micronutrientes de forma simples e múltipla, na colheita

Table 1. Production of leaves dry matter (MSFO), dry matter stem (MSCA), root dry matter (MSRA) and flowers dry matter (MSFL) from anthurium, under simple and multiple omission of micronutrients, at harvesting

\begin{tabular}{ccccc}
\hline Tratamento & MSFO $(\mathbf{g})$ & MSCA $(\mathbf{g})$ & MSRA (g) & MSFL (g) \\
\hline Completo & $30,67 \mathrm{a}$ & $9,67 \mathrm{c}$ & $4,00 \mathrm{a}$ & $8,00 \mathrm{~b}$ \\
$-\mathrm{B}$ & $28,00 \mathrm{a}$ & $9,33 \mathrm{c}$ & $2,33 \mathrm{c}$ & $4,00 \mathrm{~b}$ \\
$-\mathrm{Cu}$ & $13,00 \mathrm{~b}$ & $5,00 \mathrm{c}$ & $1,00 \mathrm{~d}$ & $5,00 \mathrm{~b}$ \\
$-\mathrm{Fe}$ & $27,67 \mathrm{a}$ & $19,33 \mathrm{a}$ & $3,33 \mathrm{~b}$ & $16,67 \mathrm{a}$ \\
$-\mathrm{Mn}$ & $16,67 \mathrm{~b}$ & $9,33 \mathrm{c}$ & $3,00 \mathrm{~b}$ & $12,67 \mathrm{a}$ \\
$-\mathrm{Zn}$ & $27,33 \mathrm{a}$ & $11,67 \mathrm{~b}$ & $2,67 \mathrm{c}$ & $7,67 \mathrm{~b}$ \\
$-\mathrm{B} \mathrm{Cu}$ & $18,33 \mathrm{~b}$ & $8,67 \mathrm{c}$ & $2,67 \mathrm{c}$ & $9,00 \mathrm{~b}$ \\
$-\mathrm{B} \mathrm{Mn}$ & $7,67 \mathrm{c}$ & $8,67 \mathrm{c}$ & $3,00 \mathrm{~b}$ & $6,33 \mathrm{~b}$ \\
$-\mathrm{B} \mathrm{Zn}$ & $26,00 \mathrm{a}$ & $12,33 \mathrm{~b}$ & $3,33 \mathrm{~b}$ & $7,00 \mathrm{~b}$ \\
$-\mathrm{Fe} \mathrm{Mn}$ & $26,67 \mathrm{a}$ & $12,67 \mathrm{~b}$ & $3,67 \mathrm{~b}$ & $12,00 \mathrm{a}$ \\
$-\mathrm{Zn} \mathrm{Cu}$ & $26,00 \mathrm{a}$ & $7,67 \mathrm{c}$ & $2,33 \mathrm{c}$ & $2,33 \mathrm{~b}$ \\
$-\mathrm{Zn} \mathrm{Cu} \mathrm{Fe}$ & $25,00 \mathrm{a}$ & $13,67 \mathrm{~b}$ & $3,67 \mathrm{~b}$ & $12,00 \mathrm{a}$ \\
\hline
\end{tabular}

Médias seguidas de mesma letra na coluna não diferem entre si pelo teste Scott e Knott a 5\%. 

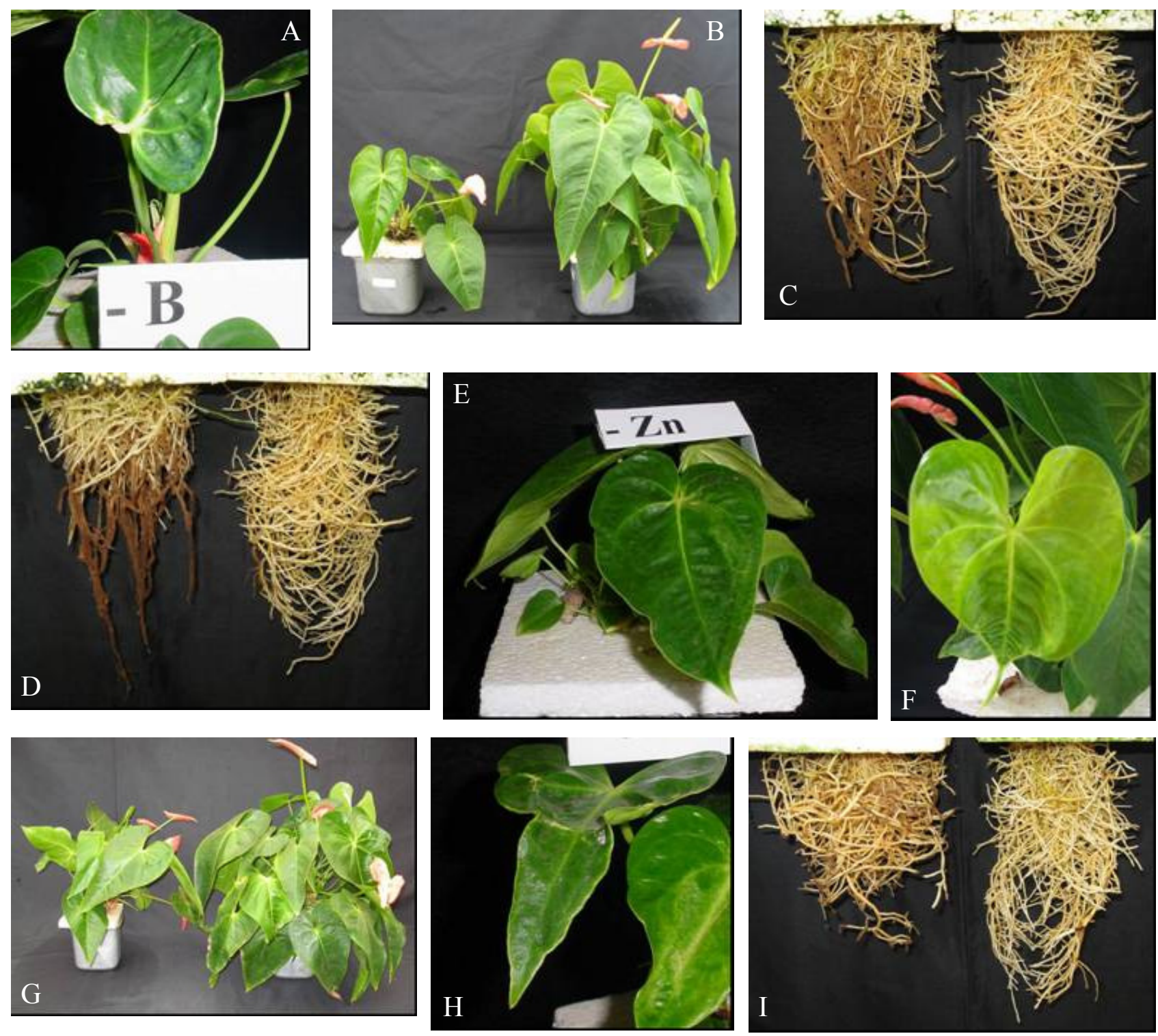

Figura 1. Sintomas visuais de deficiências de micronutrientes em plantas de antúrio: (A) aspecto da deformação da folha de planta sob deficiência de boro, (B) planta sob carência de cobre apresentando porte reduzido (esquerda) comparada com planta do tratamento completo (direita), (C) aspecto das raízes de plantas do tratamento completo (direita) e sob omissão de ferro (esquerda), (D) aspecto das raízes de plantas do tratamento completo (direita) e sob omissão de manganês (esquerda), (E) detalhe da folha de uma planta sob omissão de zinco, (F) detalhe de folha de uma planta sob omissão conjunta de boro e cobre, $(\mathrm{G})$ planta sob carência conjunta de boro e manganês apresentando porte reduzido (esquerda) comparada com planta do tratamento completo (direita), $(\mathrm{H})$ detalhe da folha mal formada de planta sob omissão conjunta de boro e zinco e (I) aspecto das raízes de plantas do tratamento completo (direita) e sob omissão de cobre e zinco (esquerda).

Figure 1. Visual symptoms of micronutrient deficiencies on anthurium: (A) aspect of the leaf deformation under boron deficiency, (B) plant under copper deficiency presenting small size (left) compared with control plant (right) (C) roots aspect of control plant (right) and under iron omission (left), (D) roots aspect of control plant (right) and under manganese omission (left), (E) detail leaf under zinc omission $(F)$ detail of leaf under multiple omission of boron and copper, $(G)$ plant under multiple deficiency of boron and manganese present small size (left) compared with the control (right)

(H) detail leaf malformed plant under multiple omission of boron and zinc and (I) aspect of the roots of control (right) and under multiple omission of copper and zinc (left). 
Tabela 2. Número de folhas (NF), largura da maior folha (LF) e comprimento da maior folha (CF) de plantas de antúrio, sob omissão de micronutrientes de forma simples e múltipla, na colheita

Table 2. Number of leaves (NF), width of largest leaf $(L F)$ and length of the longest leaf $(C F)$ from anthurium, at harvesting

\begin{tabular}{cccc}
\hline Tratamento & NF & LF & CF \\
\hline Completo & $29,33 \mathrm{a}$ & $17,00 \mathrm{~b}$ & $23,33 \mathrm{~b}$ \\
$-\mathrm{B}$ & $27,33 \mathrm{a}$ & $15,67 \mathrm{~b}$ & $21,67 \mathrm{~b}$ \\
$-\mathrm{Cu}$ & $32,00 \mathrm{a}$ & $19,00 \mathrm{a}$ & $28,00 \mathrm{a}$ \\
$-\mathrm{Fe}$ & $32,33 \mathrm{a}$ & $18,67 \mathrm{a}$ & $25,33 \mathrm{a}$ \\
$-\mathrm{Mn}$ & $19,67 \mathrm{~b}$ & $17,00 \mathrm{a}$ & $24,67 \mathrm{~b}$ \\
$-\mathrm{Zn}$ & $19,00 \mathrm{~b}$ & $18,00 \mathrm{a}$ & $25,33 \mathrm{a}$ \\
$-\mathrm{B} \mathrm{Cu}$ & $27,33 \mathrm{a}$ & $15,00 \mathrm{~b}$ & $22,00 \mathrm{~b}$ \\
$-\mathrm{B} \mathrm{Mn}$ & $23,33 \mathrm{~b}$ & $16,00 \mathrm{~b}$ & $22,33 \mathrm{~b}$ \\
$-\mathrm{Bn}$ & $39,00 \mathrm{a}$ & $16,00 \mathrm{~b}$ & $22,00 \mathrm{~b}$ \\
- - $\mathrm{Zn}$ & $21,67 \mathrm{~b}$ & $19,00 \mathrm{a}$ & $25,67 \mathrm{a}$ \\
$-\mathrm{Zn} \mathrm{Cu}$ & $14,00 \mathrm{~b}$ & $18,00 \mathrm{a}$ & $28,00 \mathrm{a}$
\end{tabular}

Médias seguidas de mesma letra na coluna não diferem entre si pelo teste Scott e Knott a 5\%. 